Tjalling C. Koopmans Research Institute Trlligh. Aoopmane

Discussion Paper Series nr: 07-14

\title{
Do Technology and Efficiency Differences determine Productivity?
}

Jaap Bos, Claire Economidou, Michael Koetter, James Kolari 


\section{Tjalling C. Koopmans Research Institute Utrecht School of Economics \\ Utrecht University}

Janskerkhof 12

3512 BL Utrecht

The Netherlands

telephone +31302539800

fax +31302537373

website www.koopmansinstitute.uu.nl

The Tjalling C. Koopmans Institute is the research institute and research school of Utrecht School of Economics.

It was founded in 2003, and named after Professor Tjalling C. Koopmans, Dutch-born Nobel Prize laureate in economics of 1975.

In the discussion papers series the Koopmans Institute publishes results of ongoing research for early dissemination of research results, and to enhance discussion with colleagues.

Please send any comments and suggestions on the Koopmans institute, or this series to s.mook@econ.uu.nl

ontwerp voorblad: WRIK Utrecht

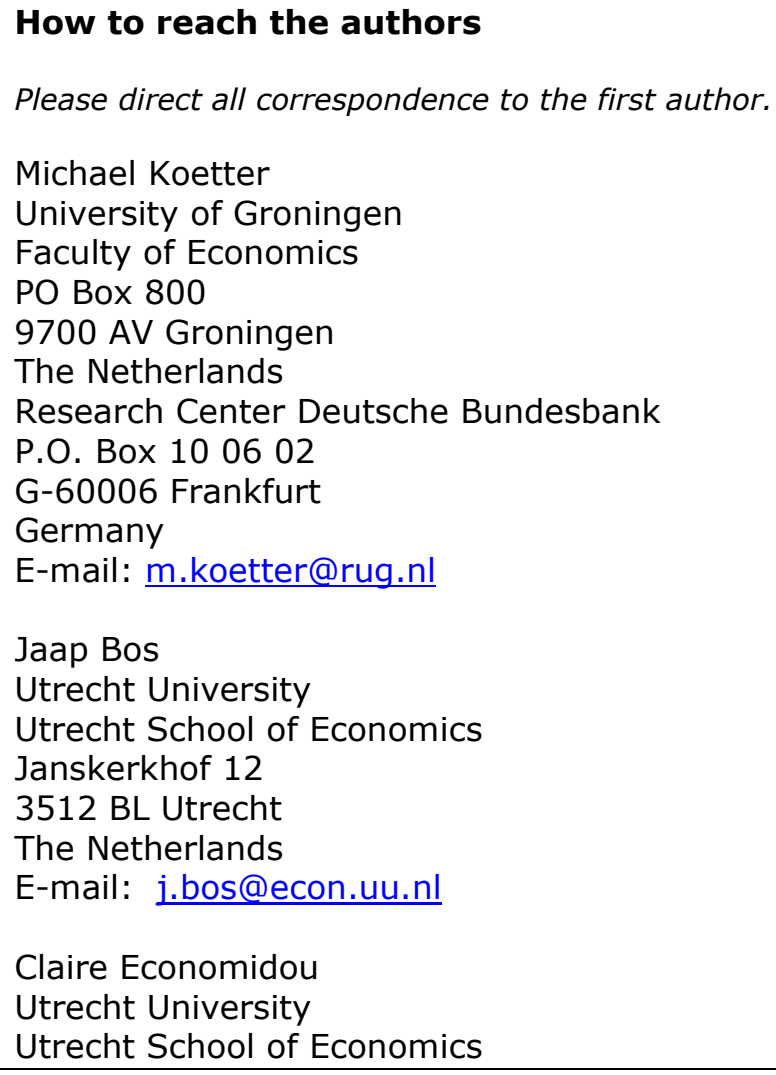


Janskerkhof 12

3512 BL Utrecht

The Netherlands

E-mail: c.economidou@econ.uu.nl

James Kolari

Mays Business School

Texas A $\ \& M$ University

4218 TAMU, College Station

Texas $77843-4218$

USA

E-mail: j-kolari@tamu.edu

This paper can be downloaded at: http://www.koopmansinstitute.uu.nl 
Utrecht School of Economics

Tjalling C. Koopmans Research Institute

Discussion Paper Series 07-14

\title{
Do Technology and Efficiency Differences determine Productivity?
}

\author{
Michael Koettera \\ Jaap Bos ${ }^{b}$ \\ Claire Economidouc \\ James Kolarid \\ ${ }^{\text {a }}$ Faculty of Economics \\ University of Groningen and \\ Research Center Deutsche Bundesbank \\ bUtrecht School of Economics \\ Utrecht University \\ 'Utrecht School of Economics \\ Utrecht University \\ dMays Business School \\ Texas A \&\&M University
}

May 2007

\begin{abstract}
This paper investigates the forces driving output growth, namely technological, efficiency, and input changes, in 80 countries over the period 1970-2000. Relevant past studies typically assume that: (i) countries use resources efficiently, and (ii) the underlying production technology is the same for all countries. We address these issues by estimating a stochastic frontier model, which explicitly accounts for inefficiency, augmented with a latent class structure, which allows for production technologies to differ across groups of countries. Membership of these groups is estimated, rather than determined ex ante. Our results indicate the existence of three groups of countries. These groups differ significantly in terms of efficiency levels, technological change, and the development of capital and labor elasticities. However, a consistent finding across groups is that growth is driven mainly by factor accumulation (capital deepening).
\end{abstract}

Keywords: Total Factor Productivity, Latent Class, Stochastic Frontier, Efficiency, Growth

JEL classification: 047, 030, D24, G21, C24

\section{Acknowledgements}

We thank Clemens Kool and seminar participants at Utrecht School of Economics for helpful comments. Michael Koetter acknowledges financial support from the Netherlands Science Foundation (NOW) under VENI grant number 016.075164. The opinions expressed are those of the authors. Any remaining errors are our own. 


\section{Introduction}

Over the past thirty years, a large amount of effort has been devoted to answering the question why some countries perform better than others. Nonetheless, growth differentials between countries still pose a puzzle to economists. Generally speaking, the empirical cross-country growth literature narrowly focuses on the role of capital in generating economic growth (Baumol, 1986; Barro, 1991, 1996; Barro and Sala-i Martin, 1992, 1994; Mankiw, Romer, and Weil, 1992; Islam, 1995). However, recent work by Prescott (1998) and Hall and Jones (1999) suggests that it is differences in productivity rather than capital that account for growth differentials. ${ }^{1}$

Previous comparative studies on cross-country growth can be divided into two strands. The first strand relies on (augmented neoclassical) production functions that assume efficient use of inputs. However, if this assumption does not hold, parameter estimates for the marginal effects of inputs are biased. The usual practice in the second strand of literature is a two-stage approach. Crosscountry productivity estimates are retrieved as a residual from a production function and then regressed on a set of potential determinants of productivity growth. ${ }^{2}$ However, in the presence of inefficiency, total factor productivity (TFP) indices based on growth accounting or index numbers (e.g. Divisia and Tornquist indices) are biased as well.

To avoid the aforementioned biases, in this paper we relax the assumption that all producers are technically efficient. We estimate a so-called stochastic production frontier, where unexplained variance consists of both random noise and inefficiency. ${ }^{3}$ Optimal behavior - the technically efficient use of the existing production technology - is represented by a production frontier that benchmarks a country against the maximum level of output it can achieve. If a country produces this optimal level of output, it is efficient and will be on the production frontier. Given their production technology and their input mix, some countries may be inefficient, and consequently produce less than their optimal output.

A major advantage of this Stochastic Frontier Analysis (SFA) framework is the

\footnotetext{
Kolari).

1 See also Coe and Helpman (1995), Keller (1997), Miller and Upadhya (2002), Scarpetta and Tressel (2002) and Griffith, Redding, and Van Reenen (2004).

2 See, for example, Coe and Helpman (1995), and Keller (1997) for the effects of domestic and foreign R\&D stocks on productivity growth. Also, see Scarpetta and Tressel (2002), Griffith (2004), and Cameron, Proudman, and Redding (2005) for the effects of $\mathrm{R} \& \mathrm{D}$, trade, and human capital on productivity growth.

3 Stochastic frontier analysis (SFA) was introduced by Aigner, Lovell, and Schmidt (1977), Battese and Corra (1977), and Meeusen and Van Den Broeck (1977).
} 
tri-partite decomposition of productivity growth into: (1) technology changes (i.e., shifts of the frontier over time), (2) factor accumulation (i.e., scale elasticity adjusted increases in factor use), and (3) inefficiency changes (i.e., movements of a country towards the production frontier). Hence, SFA results provide additional insights for designing policies with important welfare implications. For instance, among efficient countries productivity differentials can be reduced by improving the input mix or by encouraging a faster adoption of innovative technologies. However, inefficient countries can also seek to improve the efficiency with which existing technologies are used (e.g., by improving legal and financial systems, trade regulations, the quality of institutions, etc.).

In addition to assuming that all countries are efficient, most studies also assume that all countries use the same underlying production technology. The latter assumption is questionable, especially in samples that include both developed and less-developed countries. Estimating a common production function may lead to biased estimates of labor and capital elasticities. ${ }^{4}$ Some previous studies have tried to account for this bias by controlling for the quality of inputs (Koop, Osiewalski, and Steel, 2000; Limam and Miller, 2004). Other studies have excluded "excessively" different economies or ex ante classified countries. ${ }^{5}$

In this paper, we avoid assuming a common technology by estimating groupspecific production technologies using a latent class model. Countries in each group share a common production technology, but technology parameters are allowed to differ across groups. The production functions of all groups are estimated simultaneously together with group membership. ${ }^{6}$ An attractive feature of this model is that we can quantify the likelihood of group membership. We can also condition these membership probabilities on a set of covariates, such as human capital and financial development, commonly used in the growth literature (Mankiw, Romer, and Weil, 1992; Benhabib and Spiegel, 1994; King and Levine, 1993; Demirguc-Kunt and Levine, 2001).

Our empirical analysis is based on a sample of 80 countries over the period 1970-2000. We identify three groups, that are characterized by different efficiency levels, labor and capital elasticities, and levels of technological change. A consistent finding across these three groups is that growth is driven mainly by factor accumulation (capital deepening). While the level of inefficiency is substantial in one of the three groups, inefficiency changes are modest in all three groups of countries. Consequently, whereas group membership appears to be closely related to efficiency, productivity change itself is driven more

\footnotetext{
4 Moreover, if unobserved technological differences are not properly treated, they may be incorrectly identified as inefficiency.

5 See Orea and Kumbhakar (2004) for criticism.

6 In addition, we need not impose constraints on technology parameters. See Tsionas and Kumbhakar (2004).
} 
by capital deepening than by efficiency changes. An important policy implication of our findings is that highly inefficient countries need to increase their efficiency to gain the full productivity benefits of capital accumulation.

The remainder of the paper proceeds as follows. Section 2 presents the methodology and econometric specification for estimation. Section 3 introduces the data. Empirical results are presented in section 4 . Section 5 concludes.

\section{Methodology}

In this section, we begin by explaining how inefficiency is taken into account by using a stochastic frontier model. We then describe how to account for differences in technology parameters using a latent class version of the stochastic frontier model. Finally, we present the empirical specification and our decomposition of TFP growth into efficiency, factor augmentation, and technological change.

\subsection{Accounting for inefficiency}

The cross-country growth literature defines a production set consisting of the capital stock $K_{i t}$ and labor $L_{i t}$. All $N$ countries $(i=1, \ldots, N)$ in $T$ periods $(t=1, \ldots, T)$ produce real output $Y_{i t}$ using the same production function $f$, which can shift over time as a result of technological change (Solow, 1957). For a given period $t$, output differences are explained by differences in the endowments of $K_{i t}$ and $L_{i t}$, and possibly by increasing or decreasing returns to scale.

We can specify a general production function by combining the production set together with the production technology characterized by function $f$ and a parameter vector $\beta$ :

$$
Y_{i t}=f\left(K_{i t}, L_{i t}, t ; \beta\right) \cdot \exp \left\{\epsilon_{i t}\right\},
$$

where $Y_{i t}$ is the output level in country $i$ at time $t, \beta$ is a vector of parameters to be estimated, and $\exp \left\{\epsilon_{i t}\right\}$ is the exponentiated error term. In keeping with Solow (1957), we add a time trend variable $t$, which is assumed to capture neutral technological change. If all countries produce efficiently, $Y_{i t}$ is the optimal output.

However, as already mentioned, some countries may lack the ability to employ existing technologies as efficiently as possible and consequently produce less than the optimal output. The actual (observable) output $\left(Y_{i t}\right)$ produced in 
each country $i$ at time $t$ is then better described by the following stochastic frontier production function: ${ }^{7}$

$$
Y_{i t}=f\left(K_{i t}, L_{i t}, t ; \beta\right) \cdot \exp \left\{v_{i t}\right\} \cdot \exp \left\{-u_{i t}\right\}
$$

where the deterministic kernel of the production frontier $f\left(K_{i t}, L_{i t}, t ; \beta\right)$ is multiplied by an exponentiated measure of output-oriented inefficiency $-u_{i t}$ and an exponentiated noise term $v_{i t} .{ }^{8}$ Inefficiency is allowed to vary over time, and two countries with identical input levels $K_{i t}$ and $L_{i t}$ may produce different levels of output if they differ in their ability to efficiently employ the available production technology. We can write equation (2) in logs as:

$$
y_{i t}=\alpha+\beta^{\prime} x_{i t}+v_{i t}-u_{i t},
$$

where lower case letters denote natural logs, and $x$ is a vector comprising production factors. Efficiency $\left(T E_{i t}\right)$ is defined as the ratio of actual output, $y_{i t}-u_{i t}$, over optimal output, $y_{i t}$. It ranges between 0 (fully inefficient) and 1 (fully efficient), where $T E_{i t}$ of 0.9 implies that a country produces only 90 percent of optimal output. Countries that are fully efficient operate on the stochastic production frontier. Their output can only change if either the production frontier shifts through technological change or if their endowments of $K_{i t}$ and $L_{i t}$ change. Countries below the frontier can also increase their output by increasing their efficiency.

\subsection{Accounting for differences in technology parameters}

A handful of studies have examined cross-country growth differentials using stochastic frontier models. Koop, Osiewalski, and Steel (1999) study the determinants of output growth for a panel of relatively homogenous OECD countries. ${ }^{9}$ They find that capital accumulation accounts for most of the growth. Technological change plays a secondary role, and the role of efficiency growth is small. Subsequent studies analyze more countries and (consequently) attempt to control for cross-sectional heterogeneity. Koop, Osiewalski, and Steel (2000) and Limam and Miller (2004) control for the quality of production factors using efficiency units of labor and capital. ${ }^{10}$ Both studies find that factor

7 See Kumbhakar and Lovell (2000).

8 In this respect we differ from non-parametric studies (Färe, Grosskopf, Norris, and Zhang, 1994; Kumar and Russell, 2002; Los and Timmer, 2005).

9 They use a Bayesian model to obtain more robust results for their small sample.

${ }^{10}$ Koop, Osiewalski, and Steel (2000) use the years of schooling embodied in the work force to correct labor, as well as agriculture and industry labor force participation to correct physical capital. Limam and Miller (2004) use mean years of education and average age of physical capital to account for quality of labor and physical capital, respectively. 
accumulation accounts for most of the TFP growth in all groups of countries.

Tsionas and Kumbhakar (2004) suggest that one should account for crosssectional heterogeneity as well as (time) variation by estimating different technology parameters for different groups of countries. They estimate an SFA model with a Markov switching structure. ${ }^{11}$ Their results support the existence of two regimes, where most of the developed countries belong to a first regime characterized by negative growth and high efficiency. Developing countries belong to a second regime, characterized by positive growth and low levels of efficiency. The regimes differ mostly with respect to their capital intensity. As they explain, regime switching can occur in their framework due to the choice of priors in their Bayesian framework. Developing countries that switch from the second to the first regime do so by accumulating capital.

We follow a related approach, that does not require us to formulate priors. Instead, we model the regime allocation as a latent class problem. In equation (2), all countries share the same technology parameter vector $\beta$. Orea and Kumbhakar (2004) and Greene (2005) have suggested latent class frontier models as a way of relaxing this assumption. Following Greene (2005), we can write a latent class stochastic frontier model (LCFM) as:

$$
y_{i t}=\alpha+\beta_{j}^{\prime} x_{i t}+v_{i t \mid j}-u_{i t \mid j}
$$

where technology parameters $\beta$ are allowed to vary across an a priori specified number of groups $j=1, . ., J$. Greene (2005) demonstrates that countryspecific probabilities of belonging to a group $j$ can be estimated with a multinomial logit model. The conditional likelihood averaged over classes for country $i$ is:

$$
P_{i}=\sum_{j=1}^{J} \frac{\exp \left(\pi_{j} z \prime\right)}{\sum_{m=1}^{J} \exp \left(\pi_{m} z \prime\right)} \prod_{t=1}^{T} P_{i t \mid j}=\sum_{j=1}^{J} \Pi(i, j) \prod_{t=1}^{T} P_{i t \mid j}=\sum_{j=1}^{J} \Pi(i, j) P_{i \mid j} .
$$

Parameters for equations (4) and (5) can be obtained by estimating the joint likelihood incorporating production and probability parameters as described in detail in Greene (2005). ${ }^{12}$ An attractive feature of this model is that we

${ }^{11}$ Note that alternative approaches exist to allow for heterogeneity across countries'
production technologies. The simplest approach is to estimate country-specific fron-
tiers. However, since relative efficiency measures cannot be compared when derived
from different benchmarks, another approach is to use fixed or random effects panel
frontier models. While many panel models require a rigid dynamic structure on inef-
ficiency, alternatives suggested by Greene (2005) and Kumbhakar and Lovell (2000)
leave enough flexibility on the time trend of efficiency to be appropriate. However,
these models limit heterogeneity across countries to the intercept.
${ }^{12}$ We use this model suggested by Greene (2005) because the alternative approach
by Orea and Kumbhakar (2004) is sub-optimal for our purposes. In their words, "... 
can quantify the likelihood of group membership. We can also condition these membership probabilities on a set of covariates $z_{i}$.

To operationalize the model in equations (4) and (5), we need to specify a functional form. Following Kumbhakar and Wang (2005), we prefer a translog specification over a Cobb-Douglas specification due to the latter's superior flexibility (Duffy and Papageorgiou, 2000). Unlike Koop et al. (1999, 2000), we explicitly account for technology shifts in the frontier. That is, we include a trend variable $t$ with interaction terms that allows us to identify the contribution of technological change to TFP growth. The reduced form of equation (4) is then:

$$
\begin{aligned}
\ln Y_{i t} & =\alpha_{j}+\beta_{1 j} \ln K_{i t}+\beta_{2 j} \ln L_{i t}+\frac{1}{2} \beta_{11 j} \ln K_{i t}^{2} \\
& +\frac{1}{2} \beta_{22 j} \ln L_{i t}^{2}+\beta_{12 j} \ln K_{i t} \ln L_{i t}+\gamma_{1 j} t+\frac{1}{2} \gamma_{11 j} t^{2} \\
& +\delta_{1 j} \ln K_{i t} t+\delta_{2 j} \ln L_{i t} t+v_{i t}-u_{i t} .
\end{aligned}
$$

Random error $v_{i t}$ is iid with $v_{i t} \sim N\left(0, \sigma_{v}^{2}\right)$ and independent of the explanatory variables. The inefficiency term is iid with $u_{i t} \sim N\left|\left(0, \sigma_{u}^{2}\right)\right|$ and independent of $v_{i t}$. It is drawn from a non-negative distribution truncated at zero. Inefficiency is time-variant and estimated from $E\left(u_{i t} \mid \epsilon_{i t}\right)$, the conditional distribution of $u$ given $\epsilon$ (Jondrow, Lovell, Van Materov, and Schmidt, 1982). ${ }^{13}$ Efficiency $\left(T E_{i t}\right)$ is calculated as $\left[\exp \left(-u_{i t}\right)\right]$ and equals one for a fully efficient country. ${ }^{14}$

Recent studies that compare total factor productivity changes seek to account for differences in the quality of production factors by including, for example human capital and/or financial development as additional variables in the production set. ${ }^{15}$ In line with Koop, Osiewalski, and Steel (2000), we model human capital and financial development as factors that affect the labor and capital elasticities. Thus, we expect that both human capital and financial development influence output indirectly by improving the quality of labor and capital. Hence, we consider an extension of our latent class model, where human capital and financial development are included as conditioning arguments $z_{i}$ in equation (5) that help predict group memberships of individual countries. In doing so, we can test whether these factors explain differences in production technology. ${ }^{16}$

time variation [of efficiency] in this model is deterministic and evolutionary, which might or might not be restrictive" (p. 172). Put differently, in contrast to the model employed here, the $u_{i t}$ 's are not free to develop unrestricted over time in their model. ${ }^{13}$ Note that we do not impose any time trend on inefficiency, which is allowed to freely vary over time.

${ }^{14}$ To estimate the $\log$ likelihood function we re-parameterize $\sigma^{2}=\sigma_{u}^{2}+\sigma_{v}^{2}$ and $\lambda=\frac{\sigma_{u}}{\sigma v}$.

15 This approach has been criticized by Benhabib and Spiegel (1994).

${ }^{16}$ Note that we do not test whether these factors explain differences in growth developments of individual countries. 


\subsection{TFP decomposition}

Total factor productivity change $T \dot{F} P$ equals the rate of change of output $\dot{Y}$ less the rate of change of inputs $\dot{K}$ and $\dot{L}$. We follow Kumbhakar and Lovell (2000) and use the reduced form of the production frontier to decompose TFP changes into three elements. Differentiating equation (6) with respect to time yields:

$$
\begin{aligned}
T \dot{F} P & =\frac{\partial \ln f(K, L, t ; \beta)}{\partial t}-\frac{\partial u}{\partial t}+\frac{\partial \ln f(K, L, t ; \beta)}{\partial \ln K} * \frac{1}{K} \frac{d K}{d t} \\
& +\frac{\partial \ln f(K, L, t ; \beta)}{\partial \ln L} * \frac{1}{L} \frac{d L}{d t} .
\end{aligned}
$$

The first and second terms on the right-hand-side represent technological and efficiency changes, respectively. The third and fourth terms represent elasticity-adjusted factor augmentation of capital and labor, respectively.

The rate of technical change is given by $T C_{i t}=\partial \ln f\left(K_{i t}, L_{i t}, t\right) / \partial t$ in equation (7). $T \dot{C}_{i t}>0$ represents an upward shift of the production frontier. ${ }^{17}$ By taking the partial derivatives of our general index of technical change $t$ with respect to production factors $K$ and $L$, we can distinguish between pure technical change $\left(T C_{i t}^{P U}\right)$, capital augmenting technical change $\left(T C_{i t}^{K}\right)$, and labor augmenting technical change $\left(T C_{i t}^{L}\right)$ (Baltagi and Griffin, 1988). Since capital and labor elasticities are allowed to vary across groups $j$, technical change estimates are group-specific as well.

Next, consider the rate of change of efficiency $T E=\partial T E_{i t} / \partial t$ in equation (7) where efficiency levels $T E_{i t}$ are estimated simultaneously with factor elasticities, for all groups $j .{ }^{18}$ Country-specific efficiency estimates are time variant, such that a country that adopts an innovative technology but has not yet acquired the necessary skills to use it efficiently may initially have a fairly low $T E_{i t}$ compared to a country which invented the technology. Successful dissemination of that technology should be reflected in efficiency increases over time as followers catch up to innovation leaders. Note that in the latent class production frontier model, each country's change in efficiency is measured against

\footnotetext{
$\overline{17}$ Alternatively, many researchers model technical change by estimating separate frontiers per year and then disentangle output changes due to changed parameters from those due to changing variables. As discussed shortly, this is particularly problematic for the estimated inefficiency terms $u_{i t}$.

${ }^{18}$ Note that since we do not impose any particular trend on $u_{i t}$, efficiency can fluctuate freely over time. As an alternative, consider the model by Battese and Coelli (1988), where $T E_{i t}=u_{i} \cdot \gamma \cdot \exp \{-\gamma(t-T)\}$. Here the parameter $\gamma$ is identical for all countries, and $T E$ is either constantly increasing or constantly decreasing.
} 
the frontier of the group $j$ to which it belongs.

Lastly, in equation (7) the rate of change in factor augmentation is given by the sum of the scale elasticity of capital $S_{i t}^{K}=\partial \ln f(K, L, t ; \beta) / \partial \ln K *$ $(1 / K)(d K / d t)$ and labor $S_{i t}^{L}=\partial \ln f(K, L, t ; \beta) / \partial \ln L *(1 / L)(d L / d t)$ multiplied with changes in factor use, respectively. ${ }^{19}$ The rate of change in factor augmentation can vary for two reasons: pure factor accumulation and input factor elasticities. For example, if a country exhibits constant returns to scale, changes in the level of input factors do not influence the rate of change of TFP. In turn, if labor exhibits, for example, increasing returns to scale $\left(\frac{\partial \ln f(K, L, t ; \beta)}{\partial \ln L}\right)>1$, an increase in the labor force $\left(\frac{1}{L} \frac{d L}{d t}\right)>0$ further increases the rate of change of $T F P$.

Table 1

Total factor productivity decomposition

\begin{tabular}{|c|c|c|}
\hline Measure & & Calculation from Equation (7) \\
\hline & $T C_{i t}^{K}$ & $\delta_{1} \ln K_{i t}$ \\
\hline & $T C_{i t}^{L}$ & $\delta_{2} \ln L_{i t}$ \\
\hline & $T C_{i t}^{P U}$ & $\gamma_{1}+\gamma_{11} t$ \\
\hline$T C_{i t}$ & & $T C_{i t}^{P U}+T C_{i t}^{K}+T C_{i t}^{L}$ \\
\hline$T \dot{E}_{i t}$ & & $\left(\exp \left(-u_{i t}\right)\right) /\left(\exp \left(-u_{i t-1}\right)\right)-1$ \\
\hline & $S_{i t}^{K}$ & $\beta_{1}+\beta_{11} \ln K+\beta_{12} \ln L+\delta_{1} t$ \\
\hline & $\dot{S}_{i t}^{L}$ & $\beta_{2}+\beta_{22} \ln K+\beta_{12} \ln K+\delta_{2} t$ \\
\hline$\dot{S}_{i t}$ & & $S_{i t}^{K}+S_{i t}^{L}$ \\
\hline$T F P_{i t}$ & & $T \dot{C}_{i t}+T \dot{E}_{i t}+\dot{S}_{i t}$ \\
\hline
\end{tabular}

In sum, in equation (7) we decompose the rate of change in total factor productivity $T F P_{i t}$ into a technical change component, a technical efficiency component, and a scale component, all of which are conditioned on different technology parameters for $j$ groups of countries. Table 1 summarizes this decomposition for our empirical specification in equation (6).

\footnotetext{
${ }^{19}$ For expositional ease we dropped group indices $j$ but note that these scale properties are allowed to vary conditional on most likely group membership.
} 


\section{Data}

We construct a panel data set consisting of 80 countries over the period 19702000. ${ }^{20}$ Annual data are retrieved from various sources. Descriptive statistics are included in Table 5 in the Appendix. Output (Y) in terms of real gross domestic product and labor force (L) data are obtained from the Penn World Tables, version 6.1 (PWT 6.1). Total output is given by the product of the real per capita GDP, measured in 1996 international purchasing power parity dollars (chain index), and the national population numbers. Our capital stock $(\mathrm{K})$ series is computed with a perpetual inventory method following Hall and Jones (1999). ${ }^{21}$ Data on human capital, measured as the average years of education of the population that is $25+$ years old, are retrieved from Barro and Lee (2001). Finally, data on the financial development, measured as the amount of deposits held in the financial system as a percentage of GDP, are taken from Demirguc-Kunt and Levine (2001).

\section{Results}

In this section we report specification tests, discuss efficiency levels and scale elasticities, and provide decomposition results.

\subsection{Specification tests}

Before we discuss the importance of inefficiency and differences in technology in explaining growth, we must first choose our preferred specification. We do so in four steps and report results in Tables (2) and (6).

First, we test whether accounting for inefficiency can improve our analysis. To do so, we estimate a fixed effect production frontier (FEM). In estimating the frontiers, we use the following standard parameterizations: $\sigma=\left(\sigma_{u}^{2}+\sigma_{v}^{2}\right)^{1 / 2}$, and $\lambda=\sigma_{u} / \sigma_{v}$, where $\lambda$ is the ratio of inefficiency and random noise (Coelli, Rao, and Battese, 1998). We then test whether the inefficiency parameters

${ }^{20}$ The list of countries included is provided in the Appendix.

${ }^{21}$ We use a depreciation rate of $6 \%$ and utilize average growth over the first ten years to get a country-specific average growth rate. For robustness purposes, we also calculated a backward-looking capital stock using data from 1960 onwards. Results are qualitatively similar. Our capital stock series has a wider coverage than the PWT 6.1 variable for capital stock per worker, which is only available for 62 countries from 1965 onwards. Where the two series overlap, the correlation coefficient between their $\log$ levels is 0.97 . 
$\lambda$ and $\sigma$ are significantly different from zero (see Table 6 in the Appendix) and whether all parameters are jointly significantly different from zero (see the Wald test in Table 2). Both tests show that inefficiency matters, which implies that we improve upon standard production function estimations.

Second, we test whether our translog function form is indeed preferred to a Cobb-Douglas specification. Again, Wald tests for the joint significance of the additional parameters involved in estimating a translog production function are included in Table 2. Our results are consistent with Koop, Osiewalski, and Steel (1999), who also find support for the translog specification.

Table 2

Specification tests

\begin{tabular}{|c|c|c|c|c|c|}
\hline \multirow{2}{*}{$\begin{array}{l}\text { Model } \\
\text { Classes }\end{array}$} & \multirow[t]{2}{*}{ FEM } & \multicolumn{2}{|c|}{ Uncond. LCFM } & \multicolumn{2}{|c|}{ Cond. LCFM } \\
\hline & & 3 & 4 & 3 & 4 \\
\hline \multicolumn{6}{|l|}{ Hypotheses: } \\
\hline No inefficiency & 0.000 & 0.000 & 0.000 & 0.000 & 0.000 \\
\hline Cobb Douglas & 0.000 & 0.000 & 0.000 & 0.000 & 0.000 \\
\hline No additional classes & & 0.000 & 0.000 & 0.000 & 0.000 \\
\hline $\mathrm{HC}$ and $\mathrm{FD}$ & & & & 0.830 & 0.984 \\
\hline \multicolumn{6}{|c|}{ Identical group parameters on: } \\
\hline $\ln K$ & & 0.000 & $\mathrm{n} / \mathrm{a}$ & 0.000 & $\mathrm{n} / \mathrm{a}$ \\
\hline $\ln L$ & & 0.000 & $\mathrm{n} / \mathrm{a}$ & 0.000 & $\mathrm{n} / \mathrm{a}$ \\
\hline $\ln K * \ln K$ & & 0.000 & $\mathrm{n} / \mathrm{a}$ & 0.000 & $\mathrm{n} / \mathrm{a}$ \\
\hline $\ln L * \ln L$ & & 0.000 & $\mathrm{n} / \mathrm{a}$ & 0.000 & $\mathrm{n} / \mathrm{a}$ \\
\hline $\ln K * \ln L$ & & 0.000 & $\mathrm{n} / \mathrm{a}$ & 0.001 & $\mathrm{n} / \mathrm{a}$ \\
\hline$t$ & & 0.000 & $\mathrm{n} / \mathrm{a}$ & 0.000 & $\mathrm{n} / \mathrm{a}$ \\
\hline$t * t$ & & 0.000 & $\mathrm{n} / \mathrm{a}$ & 0.000 & $\mathrm{n} / \mathrm{a}$ \\
\hline $\ln K * t$ & & 0.000 & $\mathrm{n} / \mathrm{a}$ & 0.000 & $\mathrm{n} / \mathrm{a}$ \\
\hline $\ln L * t$ & & 0.001 & $\mathrm{n} / \mathrm{a}$ & 0.000 & $\mathrm{n} / \mathrm{a}$ \\
\hline$\sigma$ & & 0.000 & $\mathrm{n} / \mathrm{a}$ & 0.000 & $\mathrm{n} / \mathrm{a}$ \\
\hline$\lambda$ & & 0.000 & $\mathrm{n} / \mathrm{a}$ & 0.000 & $\mathrm{n} / \mathrm{a}$ \\
\hline
\end{tabular}

Third, we must select the number of groups in our latent class production frontier model. Theoretically, the maximum number of groups is only limited by the number of cross sections, i.e. the number of countries in our study. Empirically, over-specification problems preclude even much smaller group numbers. Greene (2005) suggests to test downward to identify the number of groups discernible in the data. In our sample, four is the maximum number of groups $j$ for which neither multicollinearity nor over-specification prohibits 
convergence of the maximum likelihood estimator. Hence, in Tables 2 and 6 we compare estimation results from specifications with three and four groups.

Our results are in favor of a specification with three groups. This specification has a higher log-likelihood value. As shown at the bottom of Table 6 , for the specification with four groups, parameter estimates of both groups one and four as well as these groups' respective membership probabilities are not significantly different from zero. Finally, while Wald tests for joint significance of parameters cannot be rejected for either specification, significance tests for individual coefficients' difference across groups are rejected for the specification with four groups. For our preferred specification with three groups, the Wald tests shown in Table 2 clearly reject the joint identity of technology parameters across groups. ${ }^{22}$

Fourth and last, we test whether our group allocation is conditional on human capital and financial development. The role of both variables in explaining growth differentials is commonly tested (see Benhabib and Spiegel (1994), de la Fuente and Domènech (2000), and Demirguc-Kunt and Levine (2001)). ${ }^{23}$ Our latent class frontier model allows us to add to these tests by exploring whether the average probability of countries belonging to our $j$ groups is affected by human capital $(H C)$ and financial development $(F D)$. Put differently, we can test whether differences in technology parameters for our groups are explained by these additional factors. In the rightmost columns of Table 6 in the Appendix, we show conditional latent class results for both three and four groups (where the last group is always the reference group). In line with Kneller and Stevens (2003), our results show that neither human capital nor financial development have discriminatory power to discern group membership probabilities in different technology groups. This result need not contradict most findings in the literature, which emphasize the relevance of both variables for economic growth. In fact, Wald tests of the joint insignificance of parameters on $F D$ and $H C$ reported in table 2 cannot be rejected despite the model's inability to generate statistically significant point estimates. We conclude that these variables may have an impact on growth when specified directly as production factors. However, they cannot predict group membership.

$\overline{22}$ The constrained specification with four groups and identical group parameters was inestimable, thus lending further support for our preferred specification. In addition to the joint equality tests of individual parameters shown in Table 2, we also test between all possible pairs of groups, e.g. whether groups three and four have the same capital elasticities. These results again show that our preferred specification with three groups has the highest discriminatory power.

${ }^{23}$ In fact, we considered a broader range of proxies, including the attainment levels (for the $15+$ and $25+$ population) and average years of education of the population that is $15+$ years old (Barro and Lee, 2001). We also considered the amount of private credit as a percentage of GDP (Demirguc-Kunt and Levine, 2001). In unreported results, our findings are qualitatively similar. 
In sum, our tests show that we indeed need to account for inefficiency and differences in technology parameters. Our preferred specification is an unconditional latent class model with three groups. Individual capital and labor elasticities are similar to previous findings in the literature yet statistically different across groups. Group membership is not conditional on human capital and financial development.

\subsection{Efficiency and scale elasticity levels}

The next step involves exploring to what extent the technology parameters and efficiency levels of our groups differ. Table 7 in the Appendix reports the classification of the three groups with different production technologies. Figure 1 visualizes the geographical grouping of countries.

Our latent class model yields a classification of countries that is in line with many previous studies that identify the U.S. and economies with a similar market structure as the economic leaders. At the same time, we should note that the most efficient countries (compared to the relevant peer group's technology) need not be those with the highest levels of income. In fact, while mean real GDP in Table 3 is highest for group one, some countries in this group have low levels of income but employ their technology very efficiently. This explains why our classification is at times substantially different from, for example, the World Bank's taxonomy.

As the TFP decomposition in Table 3 shows, group one is the most efficient compared to its own frontier. Also, factor accumulation is only marginally (during the 1970s) enhanced by positive scale elasticity. Mean technological change over the three decades is slightly negative at 0.71 percentage points. Hence, this group has all the characteristics of a mature economy. 
Figure 1. Three groups of countries with different production technologies

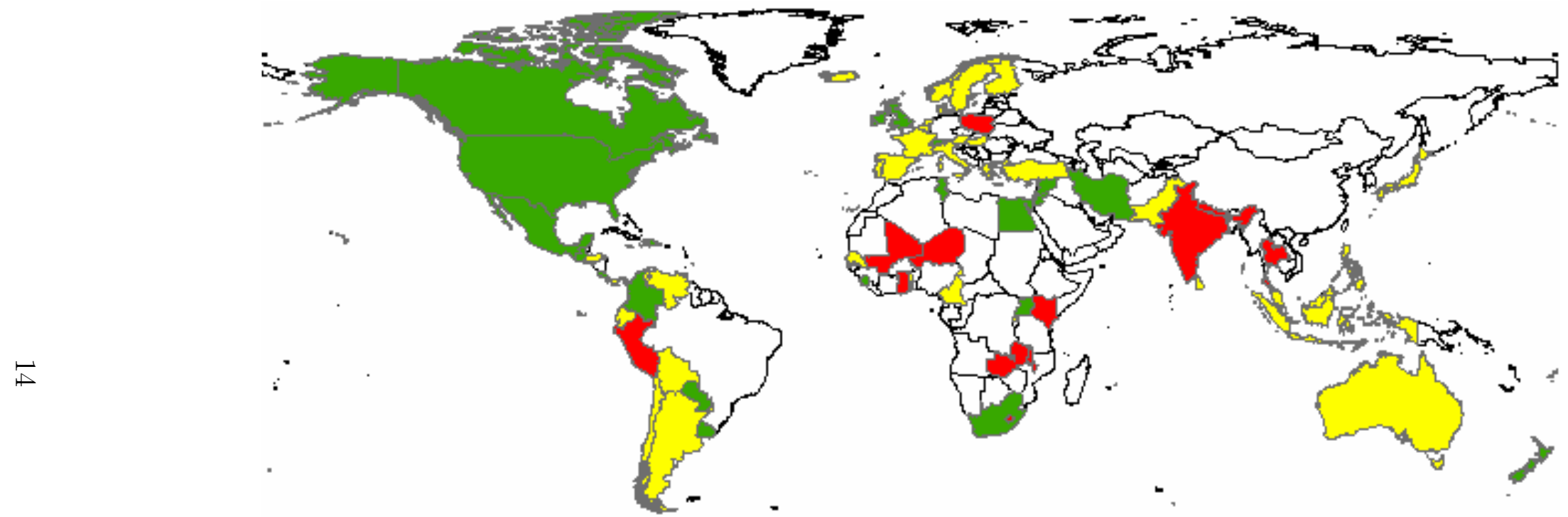
Group 1
Group 2
Group 3

Notes: See Table 7 for the list of sample countries in each group. 
In contrast, Table 3 shows that group two enjoys increasing returns to scale, implying that pure factor accumulation contributed over-proportionately to output. Efficiency levels are also fairly high for this group. And, technical change is again negative on average. This group primarily consists of countries located in continental Europe, Australasia and South America, as well as Japan. In principle, these countries may try to catch up with the leader group through factor accumulation. Whether they indeed do is discussed in the next subsection.

Like group two, scale elasticities are important for group three. In fact, over time this group evolves from producing with slightly negative scale elasticities to producing with highly positive scale elasticities, even surpassing group two. However, in this group the amount of output wasted due to inefficient production is high (approximately 20 percent of real GDP). This group consists mainly of countries located in Sub-Saharan Africa and Southeast Asia. While this indicates that policies aimed at reducing inefficiency warrant further exploration, two important caveats need to be noted. First, whether each individual country in this group should invest in reducing inefficiency or in enhancing factor accumulation or technology depends on the costs of each respective strategy. Our current analysis suggests that both strategies should be considered seriously, but does not lead to a preferred strategy. Second, the two strategies may be related. Countries that try to adopt better production technologies may temporarily experience low efficiency levels.

On average, group-specific efficiency is fairly persistent. While our efficiency levels per decade indicate that mean efficiency changes in each group were small over time, within each group there are interesting developments. For example, Figures 3 and 4 in the Appendix illustrate that some countries with low levels of efficiency in 1970 (e.g. Kenya or Venezuela) manage to improve their efficiency during the 1980s and 1990s. Over the same sample period, efficiency decreases in other economies (e.g. Thailand). Policies aimed at increasing efficiency may be either absent due to high implementation costs, or they may be unsuccessful.

In sum, our three groups differ significantly in terms of their efficiency and scale elasticity levels. Group one is mainly characterized by constant returns to scale and high levels of efficiency over time. Group two is almost as efficient as group one but exhibits increasing returns to scale. In contrast, group three is the least efficient and exhibits increasing returns to scale. We next calculate each component's contribution to TFP changes. 
Table 3

Efficiency, factor elasticities, and technical change per latent class in the period 1970-2000

\begin{tabular}{llrrrrrrrr}
\hline \multirow{2}{*}{ Decade } & Variable & \multicolumn{2}{c}{ Group 1 } & \multicolumn{2}{c}{ Group 2 } & \multicolumn{2}{c}{ Group 3 } & \multicolumn{2}{c}{ Total } \\
& & Mean & Std Dev & Mean & Std Dev & Mean & Std Dev & Mean & Std Dev \\
\hline \multirow{2}{*}{ 1970s } & Efficiency level & 0.96 & 0.01 & 0.92 & 0.05 & 0.81 & 0.13 & 0.92 & 0.08 \\
& Scale elasticity & 1.02 & 0.1 & 1.17 & 0.8 & 0.97 & 0.79 & 1.08 & 0.41 \\
& Technical change & 0.79 & 0.74 & 1.19 & 0.8 & 2.28 & 0.93 & 1.23 & 0.95 \\
& Real GDP & 116.2 & 357.9 & 68.4 & 130.3 & 31.9 & 80.5 & 78.9 & 233.9 \\
\hline \multirow{2}{*}{ 1980s } & Efficiency level & 0.96 & 0.01 & 0.94 & 0.03 & 0.82 & 0.14 & 0.92 & 0.09 \\
& Scale elasticity & 1.00 & 0.11 & 1.32 & 0.81 & 1.23 & 0.80 & 1.19 & 0.44 \\
& Technical change & -0.52 & 0.81 & -1.51 & 0.81 & -0.72 & 0.91 & -1.02 & 0.95 \\
& Real GDP & 256.6 & 816.1 & 159.2 & 306.5 & 76.8 & 201.0 & 174.4 & 526.1 \\
\hline \multirow{1990s}{*}{ Total } & Efficiency level & 0.96 & 0.01 & 0.93 & 0.04 & 0.79 & 0.16 & 0.91 & 0.1 \\
& Scale elasticity & 0.99 & 0.11 & 1.43 & 0.89 & 1.52 & 0.78 & 1.3 & 0.47 \\
& Technical change & -2.08 & 0.8 & -4.34 & 0.89 & -3.75 & 0.99 & -3.47 & 1.33 \\
& Real GDP & 460.5 & 1485.2 & 285.8 & 528.2 & 166.3 & 458.2 & 316.9 & 951.2 \\
\hline & Efficiency level & 0.96 & 0.01 & 0.93 & 0.04 & 0.80 & 0.15 & 0.91 & 0.09 \\
& Scale elasticity & 1.00 & 0.11 & 1.32 & 2.41 & 1.29 & 0.82 & 1.20 & 0.45 \\
& Technical change & -0.71 & 1.41 & -1.77 & 2.41 & -1.26 & 2.57 & -1.31 & 2.21 \\
& Real GDP & 291.1 & 1048.6 & 179.7 & 385.1 & 103.2 & 324.8 & 201.7 & 680.5 \\
\hline
\end{tabular}

Notes: Observations: 741 in group 1, 1,024 in group 2, and 445 in group 3. 


\subsection{Total factor productivity changes}

Now that we have established that there are significant differences in terms of efficiency levels and technology parameters across countries, we analyze whether these differences explain total factor productivity changes. To this end, we decompose productivity growth into the three components summarized previously in Table 1: technical growth, efficiency growth, and input growth. Table 4 reports the results of productivity decomposition by decade and country groups over the sample period.

Across all three groups, there is an average increase of 5.4 percent in total factor productivity over the period 1970-2000. The largest increase takes place in the 1970s. TFP growth in subsequent decades declines substantially to 2.3 percent during the 1990s. Figure 2 illustrates this negative development of mean TFP changes for all three groups. Two results are notable.

Figure 2. Mean TFP development per group

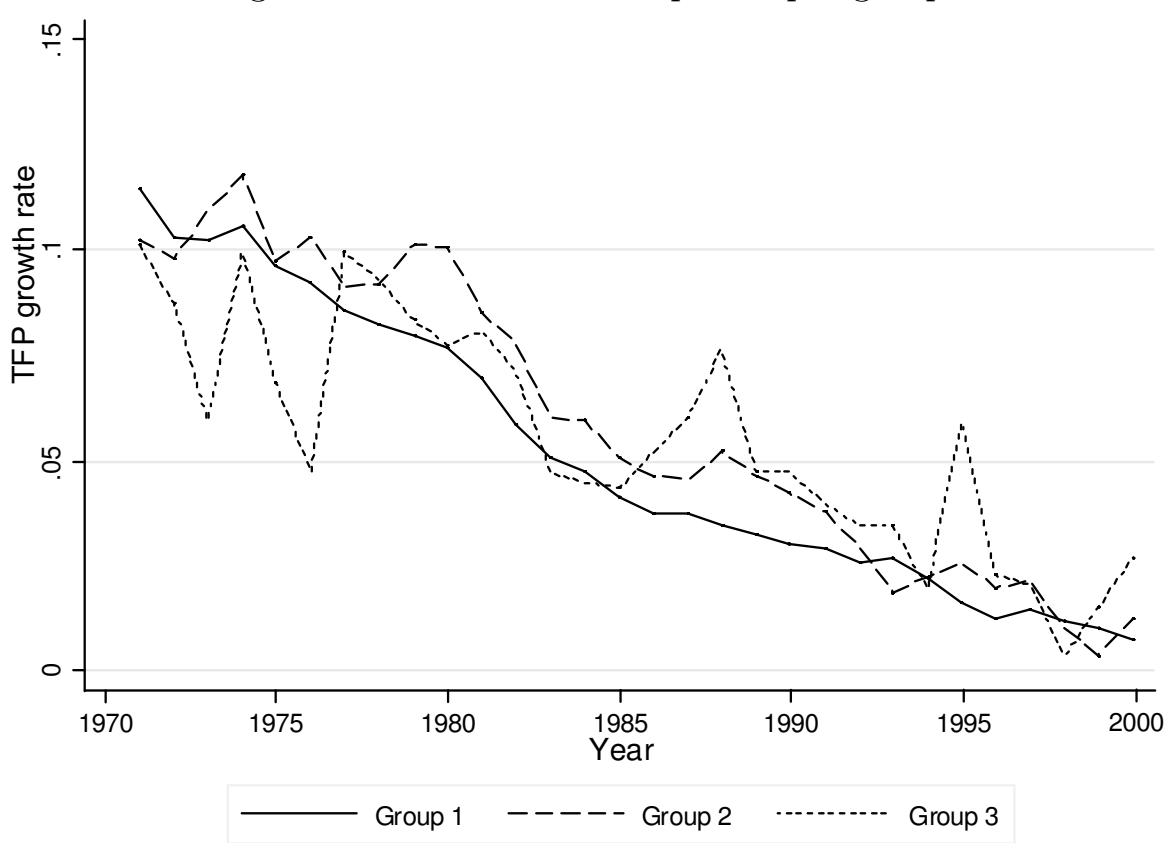

First, the dynamics with which TFP changes varies considerably across groups. While development is steady in group one, TFP changes are highly volatile in group three, and to a lesser extent in group two. For example, during the 1970s - a period characterized by two oil crises, the breakdown of exchange rate regimes, and political turmoil in Southeast Asia - TFP growth of group three countries fluctuates between 5 and 10 percent. Hence, the productivity of the least developed economies appears to be particularly sensitive to changing economic conditions. 
Table 4

Group-specific components of total factor productivity change in the period 1970-2000

\begin{tabular}{llrrrrrrrrr}
\hline \multirow{2}{*}{ Decade } & Variable & \multicolumn{2}{c}{ Group 1 } & \multicolumn{2}{c}{ Group 2 } & \multicolumn{2}{c}{ Group 3 } & \multicolumn{2}{c}{ Total } \\
& & & Mean & Std Dev & Mean & Std Dev & Mean & Std Dev & Mean & Std Dev \\
\hline \multirow{2}{*}{ 1970s } & Efficiency change & 0.03 & 0.44 & 0.03 & 2.15 & 0.68 & 6.40 & 0.14 & 3.19 \\
& Factor accumulation & 8.77 & 3.79 & 9.04 & 2.15 & 5.36 & 6.48 & 8.32 & 4.00 \\
& Technical change & 0.79 & 0.74 & 1.19 & 0.80 & 2.28 & 0.93 & 1.23 & 0.95 \\
& TFP change & 9.54 & 3.45 & 10.12 & 3.24 & 8.18 & 8.87 & 9.59 & 4.78 \\
\hline \multirow{2}{*}{ 1980s } & Efficiency change & -0.03 & 0.33 & 0.02 & 2.29 & 0.04 & 3.67 & 0.01 & 2.00 \\
& Factor accumulation & 5.42 & 2.30 & 7.69 & 2.29 & 6.60 & 5.17 & 6.71 & 3.25 \\
& Technical change & -0.52 & 0.81 & -1.51 & 0.81 & -0.73 & 0.91 & -1.02 & 0.95 \\
& TFP change & 4.88 & 2.29 & 6.20 & 3.12 & 5.90 & 6.68 & 5.70 & 3.95 \\
\hline \multirow{21990s}{*}{ Total } & Efficiency change & 0.06 & 0.45 & 0.08 & 2.19 & -0.02 & 4.69 & 0.05 & 2.42 \\
& Factor accumulation & 3.93 & 1.87 & 6.52 & 2.19 & 6.81 & 4.84 & 5.73 & 3.16 \\
& Technical change & -2.08 & 0.80 & -4.34 & 0.89 & -3.75 & 0.99 & -3.47 & 1.33 \\
& TFP change & 1.91 & 1.74 & 2.28 & 2.79 & 3.04 & 6.60 & 2.32 & 3.76 \\
\hline & Efficiency change & 0.02 & 0.41 & 0.05 & 2.43 & 0.16 & 4.83 & 0.06 & 2.53 \\
& Factor accumulation & 5.77 & 3.30 & 7.61 & 2.43 & 6.41 & 5.38 & 6.75 & 3.59 \\
& Technical change & -0.71 & 1.41 & -1.77 & 2.41 & -1.26 & 2.57 & -1.31 & 2.21 \\
& TFP change & 5.02 & 3.96 & 5.77 & 4.38 & 5.18 & 7.46 & 5.40 & 5.04 \\
\hline
\end{tabular}

Notes: Observations: 741 in group 1, 1,024 in group 2, and 445 in group 3. 
Second, throughout the sample period TFP changes tend to be largest in groups with a lower mean income. This is consistent with the notion that countries with lower productivity levels exhibit higher TFP growth. Indeed, Table 4 shows that recent TFP growth is higher in group three than in group two, whereas initial productivity levels are lower in group three. Hence, a tentative inference is that convergence between the low and medium productivity economies was more feasible in the 1990s than in earlier decades. ${ }^{24}$

As shown in Table 4, it was factor accumulation that spurred TFP growth. Efficiency changes contributed very little to total TFP growth, except for group three, which managed to increase efficiency during the 1970s. The importance of factor accumulation (capital deepening) as the major impetus for growth is consistent with other findings in the literature (Koop et al., 1999, 2000, Limam and Miller, 2003). Most of the factor accumulation takes place through the gradual increase in capital, as descriptive statistics in Table 5 demonstrate. Groups two and three benefit even more from this capital accumulation as they manage to increase their scale elasticities. However, the level of scale elasticities in group three is still rather low. Hence, these countries may need to increase their efficiency to gain the full productivity benefits of capital accumulation.

\section{Conclusion}

The standard neoclassical growth literature assumes that: (i) countries use resources efficiently, and (ii) the underlying production technology is the same for all countries. This paper tests these assumptions by estimating a latent class stochastic frontier model for a sample of 80 countries over the period 1970-2000. Our model explicitly accounts for inefficiency and allows production technologies to differ across groups of countries. Membership of these groups is estimated, rather than determined ex ante.

Specification tests show that inefficiency is significant in most countries. Inefficiency levels are particularly high for Sub-Saharan economies but also for some countries in Europe, Latin America, and Asia. Further, the assumption of a common production technology is rejected in favor of a specification with three groups of countries. These groups differ significantly in terms of efficiency levels, technological change, and the development of capital and labor elasticities. Hence, future TFP growth studies should allow for different technologies when explaining cross-country TFP growth differentials. However,

\footnotetext{
$\overline{{ }^{24} \text { Note }}$ that this is a tentative conclusion because we do not formally estimate (un)conditional convergence.
} 
group membership is not conditional on human capital or financial development.

Overall, we find that TFP growth is positive across countries but steadily declines over our sample period. Based on our empirical findings, we conclude that factor accumulation (capital deepening) is the main driver of TFP growth for all groups, since efficiency is stable over time and consequently efficiency change contributes little to TFP change. Notably, we find that efficiency is especially low in the poorest countries. As such, an important policy implication relevant to these poorest countries is that they likely would benefit from a broader spectrum of economic policies, aimed not solely at enhancing capital accumulation but also at increasing the ability to employ existing technologies more efficiently. Indeed, individual countries demonstrate that it is possible to increase efficiency and thereby achieve higher total productivity growth. 


\section{References}

Aigner, D., C. A. K. Lovell, And P. Schmidt (1977): "Formulation and Estimation of Stochastic Frontier Production Function Models," Journal of Econometrics, 6(1), 21-37.

Baltagi, B. H., and J. M. Griffin (1988): "A general index of technical change," Journal of Political Economy, 96(1), 20-41.

BARro, R. (1991): "Economic Growth in a Cross Section of Countries," The Quarterly Journal of Economics, 106(2), 407-443.

(1996): "Determinants of Economic Growth: A Cross-Country Empirical Study," NBER Working Paper, 5698.

Barro, R., And X. SAla-I Martin (1992): "Convergence," Journal of Political Economy, 100(2), 223-251.

(1994): "Quality Improvements in Models of Growth," NBER Working Papers, 4610.

Barro, R. J., and J.-W. Lee (2001): "International Data on Educational Attainment: Updates and Implications," Oxford Economic Papers, 53(3), $541-563$.

Battese, G., And G. Corra (1977): "Estimation of a Production Frontier Model: With Application to the Pastoral Zone of Eastern Australia," Australian Journal of Agricultural Economics, 21, 169-179.

Battese, G. E., And T. J. Coelli (1988): "Prediction of Firm-Level Technical Efficiencies with a Generalized Frontier Production Function and Panel Data," Journal of Econometrics, 38(3), 387-399.

Baumol, W. (1986): "Productivity Growth, Convergence, and Welfare: What the Long-run Data Show," American Economic Review, 76(5), 1072-1085.

Benhabib, J., And M. M. Spiegel (1994): "The Role of Human Capital in economic Development: Evidence from Aggregate Cross-Country Data," Journal of Monetary Economics, 34(2), 363-390.

Cameron, G., J. Proudman, and S. Redding (2005): "Technological Convergence, R\&D, Trade and Productivity Growth," European Economic Review, 49(3), 775-807.

Coe, D. T., And E. Helpman (1995): "International R\&D spillovers," European Economic Review, 39(5), 859-887.

Coelli, T., D. P. Rao, and G. E. Battese (1998): An Introduction to Efficiency Analysis. Kluwer Academic Publishers, Boston/Dordrecht/London.

DE LA Fuente, A., And R. Domènech (2000): "Human capital in growth regressions: How much difference does data quality make?," OECD Working Paper Series, 262.

Demirguc-Kunt, A., And R. Levine (2001): Financial Structure and Economic Growth: A Cross-Country Comparison of Banks, Markets, and Development. MIT Press, Cambridge, MA.

Duffy, G., and C. Papageorgiou (2000): "A Cross-Country Empirical Investigation of the Aggregate Production Function Specification," Journal of Economic Growth, 5(1), 87-120. 
Färe, R. J., S. Grosskopf, M. Norris, and Z. Zhang (1994): "Productivity Growth, Technical Progress, and Efficiency Change in Industrialized Countries," American Economic Review, 84(1), 66-83.

Greene, W. (2005): "Reconsidering Heterogeneity in Panel Data Estimators of the Stochastic Frontier Model," Journal of Econometrics, 126(2), 269303.

Griffith, R. (2004): "Ownership and Productivity: New Evidence from the Service Sector and the R\&D Lab," Oxford Review of Economic Policy, 20(3), 440-456.

Griffith, R., S. Redding, and J. Van Reenen (2004): "Mapping the two faces of R\&D: Productivity Growth in a Panel of OECD Industries," Review of Economics and Statistics, 86(4), 883-895.

Hall, R., and C. Jones (1999): "Why Do Some Countries Produce So Much More Output Per Worker Than Others?," The Quarterly Journal of Economics, 114(1), 83-116.

Islam, N. (1995): "Growth Empirics: A Panel Data Approach," The Quarterly Journal of Economics, 110(4), 1127-1170.

Jondrow, J., C. A. K. Lovell, S. Van Materov, and P. Schmidt (1982): "On the Estimation of Technical Inefficiency in the Stochastic Frontier Production Function Model," Journal of Econometrics, 19(2-3), 233238.

KelleR, W. (1997): "Do trade patterns and technology flows affect productivity growth," World Bank Economic Review, 14(1), 17-47.

King, R., And R. Levine (1993): "Finance and Growth: Schumpeter Might be Right," Journal of Monetary Economics, 32(3), 513-542.

Kneller, R., And P. A. Stevens (2003): "Absorptive Capacity and Frontier Technology: Evidence from OECD Manufacturing Industries," University of Nottingham Research Paper Series, 13.

Koop, G., J. Osiewalski, And M. F. Steel (1999): "The Components of Output Growth: A Stochastic Frontier Analysis," Oxford Bulletin of Economics and Statistics, 61(4), 455-487.

— (2000): "Modeling the Sources of Output Growth in a Panel of Countries," Journal of Business and Economic Statistics, 18(3), 284-299.

Kumar, S., And R. R. Russell (2002): "Technological Change, Technological Catch-up, and Capital Deepening: Relative Contributions to Growth and Convergence," American Economic Review, 92(3), 527-548.

KumbHakaR, S., AND H.-J. WANG (2005): "Estimation of growth convergence using a stochastic production frontier approach," Economics Letters, 88(3), 300-305.

Kumbhakar, S. C., And C. A. K. Lovell (2000): Stochastic Frontier Analysis. Cambridge University Press, Cambridge.

Limam, Y. R., And S. M. Miller (2004): "Explaining Economic Growth: Factor Accumulation, Total Factor Productivity Growth, and Production Efficiency Improvement," University of Connecticut Working Paper, 20.

Los, B., And M. P. Timmer (2005): "The appropriate technology explana- 
tion of productivity growth differentials: An empirical approach," Journal of Development Economics, 77(2), 517-531.

Mankiw, N. G., D. Romer, and D. Weil (1992): "A Contribution to the Empirics of Economic Growth," The Quarterly Journal of Economics, $107(2), 407-437$.

Meeusen, W., and J. Van Den Broeck (1977): "Efficiency Estimation for Cobb-Douglas Production Functions with Composed Error," International Economic Review, 18(2), 435-444.

Miller, S., And M. UpadhyA (2002): "Total Factor Productivity, Human Capital and Outward Orientation: Differences by Stage of Development and Geographic Regions," University of Connecticut Working Paper, 33.

Orea, L., And S. KumbhaKar (2004): "Efficiency measurement using a latent class stochastic frontier model," Empirical Economics, 29 (1), 169183.

Prescott, E. (1998): "Needed: A Theory of Total Factor Productivity," International Economic Review, 39(3), 525-551.

Scarpetta, S., and T. Tressel (2002): "Productivity and Convergence in a Panel of OECD Industries: Do Regulations and Institutions Matter?," OECD Economics Department Working Papers, 342.

Solow, R. A. (1957): "Technical Change and Aggregate Production Function," Review of Economics and Statistics, 39(3), 312-320.

Tsionas, E., And S. KumbHakar (2004): "Markov switching stochastic frontier model," Econometrics Journal, 7(2), 398-425. 


\section{Appendix}

Table 5

Descriptive statistics

\begin{tabular}{llrrrr}
\hline Variable & & Mean & Std Dev & Min & Max \\
\hline 1970s (n=631) & & & & & \\
\hline Real GDP & $Y$ & 78.88 & 233.87 & 0.3573 & 2544.5 \\
Capital stock & $K$ & 15.45 & 41.38 & 0.0035 & 407.2 \\
Labor force & $L$ & 11.97 & 33.18 & 0.0884 & 259.9 \\
Financial development & $F D$ & 31.63 & 22.00 & 0.0175 & 129.3 \\
Human capital & $H C$ & 4.56 & 2.81 & 0.0420 & 11.5 \\
\hline 1980s (n=733) & & & & & 5439.7 \\
\hline Real GDP & $Y$ & 174.43 & 526.13 & 0.7056 & 1265.0 \\
Capital stock & $K$ & 42.04 & 124.38 & 0.0176 & 324.7 \\
Labor force & $L$ & 13.11 & 37.54 & 0.1174 & 172.3 \\
Financial development & $F D$ & 38.46 & 26.52 & 1.9356 & 11.9 \\
Human capital & $H C$ & 5.23 & 2.88 & 0.3860 & \\
\hline 1990s (n=846) & & & & & 3010.2 \\
\hline Real GDP & $Y$ & 316.86 & 951.22 & 1.0031 & 405.2 \\
Capital stock & $K$ & 96.21 & 297.80 & 0.0769 & 199.9 \\
Labor force & $L$ & 15.72 & 44.90 & 0.1289 & 12.3 \\
Financial development & $F D$ & 43.72 & 30.71 & 3.4792 & \\
Human capital & $H C$ & 6.05 & 2.89 & 0.5470 & \\
\hline Notes $Y=G D P$ & & &
\end{tabular}

Notes: $Y=$ GDP in billions of 1996 PPP dollars; $K=$ capital stock

constructed as in Hall and Jones (1999); $L=$ labor force from PWT61;

$H C=$ average years of education $25+$ as in Barro and Lee (2001);

$F D=$ financial system deposits/GDP as in Demirguc-Kunt and Levine (2001). 
Figure 3. Efficiency levels in 1970
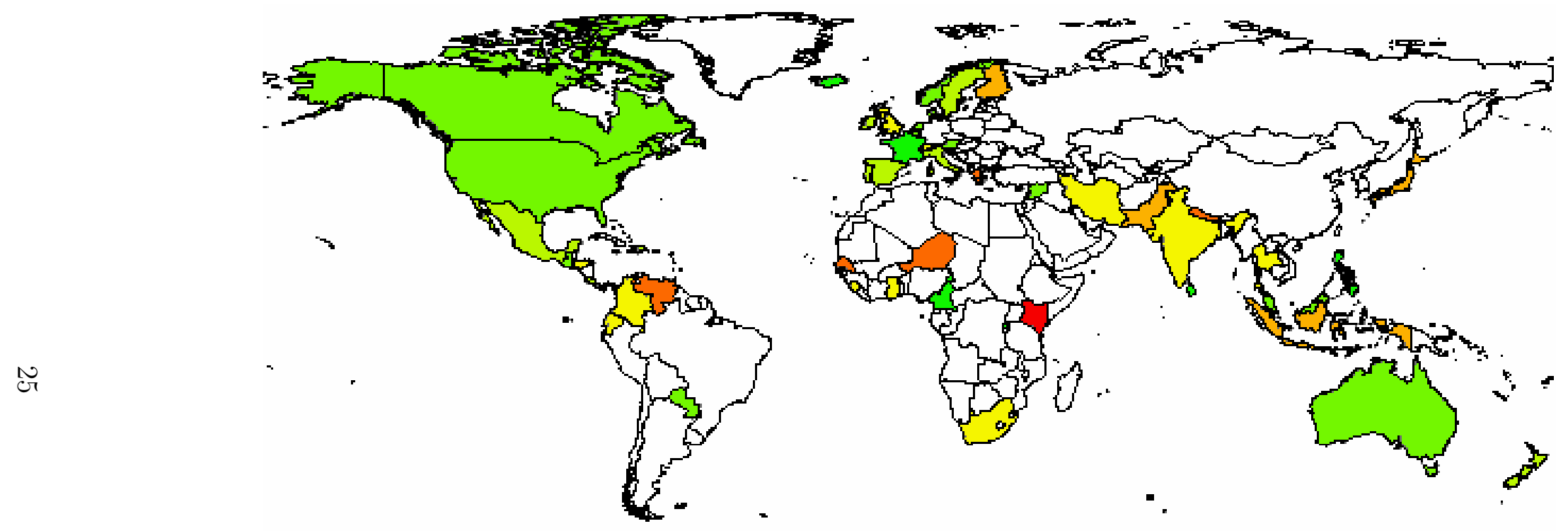

49.6 to 59.7

91.9 to 94.9

97.4 to 98.2 
Figure 4. Efficiency levels in 2000
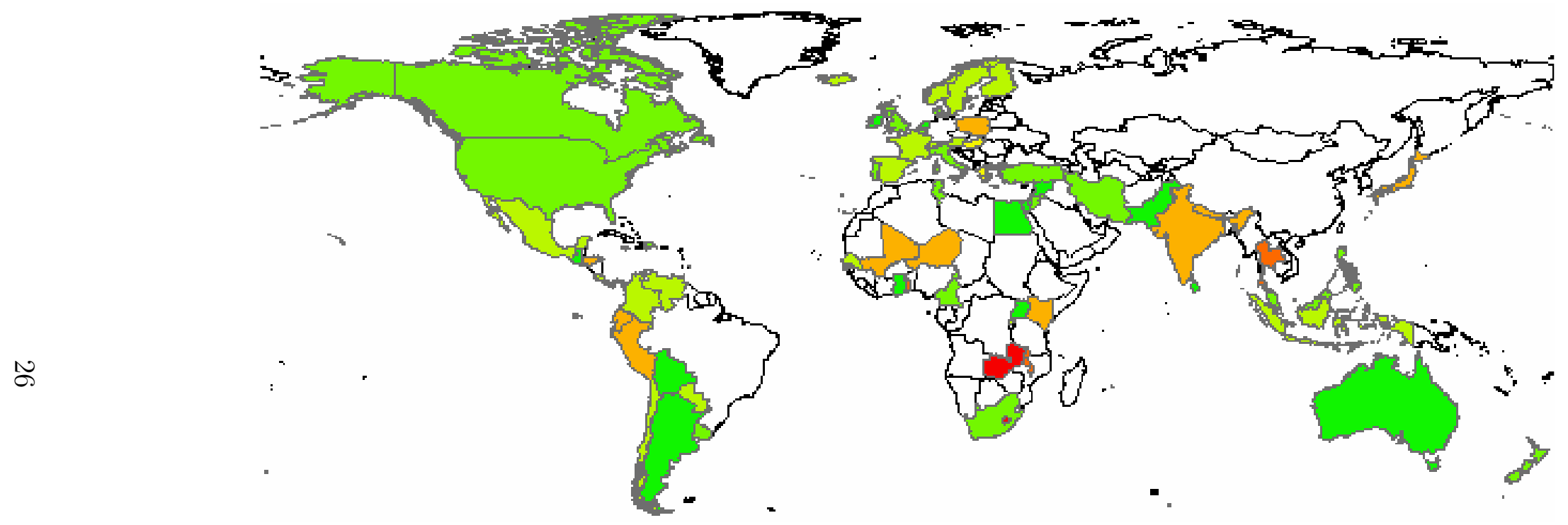

33.1 to 57.6

88.9 to 92.0

96.5 to 97.9

Notes: Sample countries' efficiency levels. 
Table 6

Parameter estimates

\begin{tabular}{|c|c|c|c|c|c|c|c|c|c|c|}
\hline \multirow{4}{*}{$\begin{array}{l}\text { Model } \\
\text { Groups } \\
\text { Log Likelihood }\end{array}$} & \multirow{3}{*}{\multicolumn{2}{|c|}{$\begin{array}{l}\text { FEM } \\
1 \\
50.3\end{array}$}} & \multicolumn{4}{|c|}{ Unconditional LCM } & \multicolumn{4}{|c|}{ Conditional LCM } \\
\hline & & & \multirow{2}{*}{\multicolumn{2}{|c|}{$\begin{array}{l}3 \\
927.1\end{array}$}} & \multirow{2}{*}{\multicolumn{2}{|c|}{$\begin{array}{l}4 \\
792.1\end{array}$}} & \multirow{2}{*}{\multicolumn{2}{|c|}{$\begin{array}{l}3 \\
1139.1\end{array}$}} & 4 & \\
\hline & & & & & & & & & \multicolumn{2}{|c|}{1229.4} \\
\hline & $\beta$ & $p$-value & $\beta$ & $p$-value & $\beta$ & $p$-value & $\beta$ & $p$-value & $\beta$ & $p$-value \\
\hline$\alpha$ & & & -0.230 & 0.000 & 0.194 & 1.000 & -0.269 & 1.000 & -0.334 & 0.052 \\
\hline $\ln K$ & 0.494 & 0.000 & 0.475 & 0.000 & 0.665 & 0.989 & 0.533 & 0.000 & 0.435 & 0.000 \\
\hline $\ln L$ & 0.469 & 0.000 & 0.467 & 0.000 & 0.157 & 0.998 & 0.296 & 0.000 & 0.388 & 0.000 \\
\hline $\ln K * \ln K$ & 0.013 & 0.000 & -0.027 & 0.000 & -0.017 & 0.999 & -0.005 & 0.001 & -0.007 & 0.517 \\
\hline $\ln L * \ln L$ & -0.020 & 0.000 & 0.042 & 0.000 & -0.026 & 1.000 & 0.166 & 0.000 & 0.198 & 0.000 \\
\hline $\ln K * \ln L$ & 0.018 & 0.000 & 0.019 & 0.000 & 0.041 & 0.999 & -0.031 & 0.000 & -0.036 & 0.003 \\
\hline$t$ & 0.034 & 0.000 & 0.021 & 0.000 & -0.014 & 0.998 & 0.021 & 0.000 & 0.033 & 0.000 \\
\hline$t * t$ & -0.002 & 0.000 & -0.001 & 0.000 & 0.001 & 0.996 & -0.001 & 0.000 & -0.002 & 0.000 \\
\hline $\ln K * t$ & 0.004 & 0.000 & 0.005 & 0.000 & -0.008 & 0.997 & 0.005 & 0.000 & 0.007 & 0.000 \\
\hline $\ln L * t$ & -0.007 & 0.000 & -0.005 & 0.000 & 0.012 & 0.997 & -0.003 & 0.000 & -0.005 & 0.000 \\
\hline$\sigma$ & 0.578 & 0.000 & 0.188 & 0.000 & 0.158 & 0.987 & 0.152 & 0.783 & 0.139 & 0.003 \\
\hline$\lambda$ & 2.519 & 0.000 & 0.653 & 0.021 & 0.000 & 1.000 & 0.000 & 1.000 & 0.395 & 0.817 \\
\hline$\alpha$ & & & -0.554 & 0.000 & -0.794 & 0.000 & -0.493 & 0.000 & -0.971 & 0.648 \\
\hline $\ln K$ & & & 0.586 & 0.000 & 0.606 & 0.000 & 0.551 & 0.000 & 0.778 & 0.605 \\
\hline $\ln L$ & & & 0.391 & 0.000 & 0.347 & 0.000 & 0.345 & 0.000 & 0.260 & 0.972 \\
\hline $\ln K * \ln K$ & & & 0.045 & 0.000 & 0.086 & 0.000 & -0.003 & 0.386 & 0.226 & 0.212 \\
\hline $\ln L * \ln L$ & & & 0.047 & 0.000 & 0.169 & 0.000 & 0.062 & 0.000 & 0.481 & 0.908 \\
\hline $\ln K * \ln L$ & & & -0.043 & 0.000 & -0.108 & 0.000 & -0.009 & 0.091 & -0.184 & 0.925 \\
\hline$t$ & & & 0.028 & 0.000 & 0.030 & 0.000 & 0.027 & 0.000 & -0.005 & 0.970 \\
\hline$t * t$ & & & -0.001 & 0.000 & -0.001 & 0.000 & -0.002 & 0.000 & 0.001 & 0.947 \\
\hline $\ln K * t$ & & & 0.001 & 0.000 & 0.000 & 0.625 & 0.006 & 0.000 & -0.010 & 0.932 \\
\hline $\ln L * t$ & & & -0.001 & 0.000 & 0.000 & 0.942 & -0.006 & 0.000 & -0.003 & 0.992 \\
\hline$\sigma$ & & & 0.177 & 0.000 & 0.173 & 0.000 & 0.266 & 0.000 & 0.390 & 0.791 \\
\hline$\lambda$ & & & 2.168 & 0.000 & 1.591 & 0.000 & 3.420 & 0.000 & 7.889 & 0.985 \\
\hline$\alpha$ & & & -1.032 & 0.000 & -0.340 & 0.000 & -1.041 & 0.000 & -0.491 & 0.000 \\
\hline $\ln K$ & & & 0.556 & 0.000 & 0.494 & 0.000 & 0.724 & 0.002 & 0.562 & 0.000 \\
\hline $\ln L$ & & & 0.273 & 0.000 & 0.402 & 0.000 & 0.145 & 0.547 & 0.391 & 0.000 \\
\hline $\ln K * \ln K$ & & & 0.111 & 0.000 & -0.002 & 0.362 & 0.174 & 0.000 & 0.037 & 0.000 \\
\hline $\ln L * \ln L$ & & & 0.133 & 0.000 & -0.048 & 0.000 & 0.162 & 0.000 & 0.033 & 0.000 \\
\hline $\ln K * \ln L$ & & & -0.093 & 0.000 & 0.044 & 0.000 & -0.102 & 0.005 & -0.029 & 0.000 \\
\hline$t$ & & & 0.041 & 0.000 & 0.023 & 0.000 & 0.015 & 0.508 & 0.026 & 0.000 \\
\hline$t * t$ & & & -0.002 & 0.007 & -0.001 & 0.000 & 0.000 & 0.952 & -0.002 & 0.000 \\
\hline $\ln K * t$ & & & 0.001 & 0.549 & 0.004 & 0.000 & -0.006 & 0.472 & 0.003 & 0.000 \\
\hline $\ln L * t$ & & & 0.000 & 0.855 & -0.006 & 0.000 & 0.000 & 0.973 & -0.002 & 0.000 \\
\hline$\sigma$ & & & 0.420 & 0.000 & 0.176 & 0.000 & 0.390 & 0.000 & 0.167 & 0.000 \\
\hline$\lambda$ & & & 7.576 & 0.000 & 1.238 & 0.000 & 16.686 & 0.655 & 1.985 & 0.000 \\
\hline$\alpha$ & & & & & -1.704 & 1.000 & & & -1.152 & 0.937 \\
\hline $\ln K$ & & & & & 0.333 & 1.000 & & & 0.536 & 0.830 \\
\hline $\ln L$ & & & & & 0.313 & 1.000 & & & 0.332 & 0.972 \\
\hline $\ln K * \ln K$ & & & & & 0.057 & 1.000 & & & 0.106 & 0.478 \\
\hline $\ln L * \ln L$ & & & & & 0.305 & 1.000 & & & 0.074 & 0.780 \\
\hline $\ln K * \ln L$ & & & & & -0.068 & 1.000 & & & -0.047 & 0.939 \\
\hline$t$ & & & & & 0.064 & 1.000 & & & 0.038 & 0.971 \\
\hline$t * t$ & & & & & -0.002 & 1.000 & & & -0.001 & 0.979 \\
\hline $\ln K * t$ & & & & & 0.006 & 1.000 & & & -0.006 & 0.867 \\
\hline $\ln L * t$ & & & & & -0.002 & 1.000 & & & 0.001 & 0.998 \\
\hline$\sigma$ & & & & & 0.254 & 0.998 & & & 0.153 & 0.947 \\
\hline$\lambda$ & & & & & 6.055 & 1.000 & & & 1.036 & 0.981 \\
\hline$P($ Group 1$)$ & & & 0.327 & 0.000 & 0.107 & 1.000 & & & & \\
\hline$P($ Group 2$)$ & & & 0.448 & 0.000 & 0.252 & 0.001 & & & & \\
\hline$P($ Group 3$)$ & & & 0.225 & 0.000 & 0.468 & 0.000 & & & & \\
\hline$P($ Group 4$)$ & & & & & 0.174 & 0.999 & & & & \\
\hline$\alpha_{1}$ & & & & & & & 1.306 & 0.825 & -2.649 & 0.989 \\
\hline $\ln F D$ & & & & & & & -0.329 & 0.879 & 0.057 & 0.999 \\
\hline $\ln H C$ & & & & & & & 0.580 & 0.840 & 1.821 & 0.989 \\
\hline$\alpha_{2}$ & & & & & & & 1.905 & 0.751 & -0.231 & 1.000 \\
\hline $\ln F D$ & & & & & & & -0.208 & 0.922 & 0.044 & 1.000 \\
\hline $\ln H C$ & & & & & & & -0.110 & 0.966 & -0.017 & 1.000 \\
\hline$\alpha_{3}$ & & & & & & & contro & group & -0.380 & 0.998 \\
\hline $\ln F D$ & & & & & & & contro & group & -0.254 & 0.998 \\
\hline $\ln H C$ & & & & & & & contro & group & 1.357 & 0.991 \\
\hline$\alpha_{4}$ & & & & & & & & & cont & coup \\
\hline $\begin{array}{l}\ln F D \\
\ln H C\end{array}$ & & & & & & & & & $\begin{array}{l}\text { cont } \\
\text { cont }\end{array}$ & roup \\
\hline $\ln H C$ & & & & & & & & & cont & roup \\
\hline
\end{tabular}

Notes: Number of countries $=80$; Observations $=2,210$. FEM $=$ fixed effect panel frontier model; and LCFM $=$ latent class frontier model. Standard parameterizations: $\sigma=\left(\sigma_{u}^{2}+\sigma_{v}^{2}\right)^{1 / 2}$, and $\lambda=\sigma_{u} / \sigma_{v}$. 
Table 7

Groups of countries with a common production technology

\begin{tabular}{|c|c|c|c|c|c|}
\hline Group 1 & $\mathrm{n}$ & Group 2 & $\mathrm{n}$ & Group 3 & $\mathrm{n}$ \\
\hline Barbados & 31 & Argentina & 13 & Central African Republic & 17 \\
\hline Canada & 31 & Australia & 31 & Cyprus & 27 \\
\hline Colombia & 27 & Austria & 29 & Gambia & 26 \\
\hline Costa Rica & 31 & Belgium & 29 & Ghana & 31 \\
\hline Dominican Republic & 31 & Bolivia & 17 & India & 31 \\
\hline Egypt & 26 & Botswana & 25 & Jamaica & 31 \\
\hline El Salvador & 31 & Cameroon & 31 & Kenya & 31 \\
\hline Guatemala & 31 & Chile & 27 & Lesotho & 25 \\
\hline Haiti & 29 & Denmark & 31 & Malawi & 20 \\
\hline Iran & 26 & Ecuador & 31 & Mali & 13 \\
\hline Ireland & 31 & Fiji & 30 & Nepal & 31 \\
\hline Jordan & 24 & Finland & 31 & Niger & 31 \\
\hline Mauritius & 31 & France & 29 & Papua New Guinea & 26 \\
\hline Mexico & 31 & Greece & 31 & Peru & 12 \\
\hline New Zealand & 31 & Honduras & 31 & Poland & 20 \\
\hline Paraguay & 31 & Hungary & 18 & Singapore & 27 \\
\hline Sierra Leone & 27 & Iceland & 29 & Thailand & 31 \\
\hline South Africa & 29 & Indonesia & 31 & Zambia & 15 \\
\hline Switzerland & 31 & Israel & 25 & & \\
\hline Syria & 31 & Italy & 31 & & \\
\hline Trinidad \& Tobago & 31 & Japan & 31 & & \\
\hline Tunisia & 13 & Malaysia & 31 & & \\
\hline Uganda & 19 & Netherlands & 29 & & \\
\hline United Kingdom & 31 & Norway & 31 & & \\
\hline United States & 31 & Pakistan & 31 & & \\
\hline \multirow[t]{11}{*}{ Uruguay } & 25 & Panama & 31 & & \\
\hline & & Philippines & 31 & & \\
\hline & & Portugal & 31 & & \\
\hline & & Rwanda & 29 & & \\
\hline & & Senegal & 31 & & \\
\hline & & Spain & 31 & & \\
\hline & & Sri Lanka & 31 & & \\
\hline & & Sweden & 31 & & \\
\hline & & Togo & 30 & & \\
\hline & & Turkey & 14 & & \\
\hline & & Venezuela & 31 & & \\
\hline
\end{tabular}

Notes: The number of observations by country group is as follows: $n=741$ in group $1, \mathrm{n}=1,024$ in group 2 , and $\mathrm{n}=445$ in group 3 . 